Jurnal Kejaora: Jurnal Kesehatan Jasmani dan Olah Raga

ISSN: 2541-5042 (Online)

ISSN: 2503-2976 (Print)

Volume 6 Nomor 1, Edisi April 2021

\title{
MODEL PEMBELAJARAAN JARAK PENDEK PADA SISWA SEKOLAH MENENGAH PERTAMA
}

\section{Akis Mayanto ${ }^{1}$, Muhamad Syamsul Taufik², Adi Wijayanto ${ }^{3}$, Soleh Solahudin ${ }^{4}$, Bangkit Seandi Taroreh ${ }^{5}$}

1Pendidikan Guru Sekolah Dasar Universitas Muhadi Setiabudi, Indonesia 2Pendidikan Jasmani Kesehatan dan Rekreasi, Universitas Suryakancana, Indonesia ${ }^{3}$ Prodi Pendidikan Guru Madrasah Ibtidaiyah, Fakultas Tarbiyah dan IImu Keguruan 4Pendidikan Jasmani Kesehatan dan Rekreasi, Universitas Sriwijaya, Indonesia 5Universitas Bina Dharma Palembang, Indonesia

E-mail: akismayanto@umus.ac.id1', syamsul@unsur.ac.id², adiwijayanto@iain-tulungagung.ac.id³, solehsolahuddin@fkip.unsri.ac.id ${ }^{4}$, bangkitseanditaroreh@binadarma.ac.id ${ }^{5}$

\section{DOI: https://doi.org/10.36526/kejaora.v6i1.1174}

\begin{abstract}
ABSTRAK
Tujuan Penelitian ini adalah menghasilkan produk baru yang dipakai dalam pembelajaran lari jarak pendek pada siswa SMP, Penelitian ini merupakan jenis peneltiian pengembangan dengan metode RND dari Borg and Gall, subjek penelitian ini adalah 120 siswa sekolah menengah pertama yatu tiga sekolah di kabupaten Bogor. Sekolah Menengah Pertama Negeri 2 Ciawi Bogor, Sekolah Menengah Pertama Negeri 1 Ciawi Bogor dan Sekolah Menengah Pertama Negeri 3 Ciawi Bogor. Teknik Pengumpulan data dengan cara observasi, studi dokumentasi, wawancara dan tes, analisis data dilakukan secara kualitatif dan kuantitatif, pengembangan model melalui uji coba terbatas, uji coba luas dan uji efektiifitas. Hasil statistik dengan uji signifikansi perbedaan dengan SPSS 16 dapat hasil nilai $t-23.542$ taraf signifikasni 0,05 dengan $p$-value $=0.00<0.05$ yang berarti terdapat perbedaan yang signifikan antara model sebelum dan sesudah diberi model pembelajaran untuk sekolah menengah pertama pada lari jarak pendek, dapat disimpulkan (1) Model pembelajran lari jarak pendek dapat diterapkan pada siswa sekolah menengah pertama (2) Model pembelajran lari jarak pendek efektif dapat meningkatkan hasil belajar lari jarak pendek pada siswa sekolah menengah pertama.
\end{abstract}

Kata Kunci: Model Pembelajaran, Lari Jarak Pendek, Siswa

\section{PENDAHULUAN}

Model Pembelajaran Belajar mempunyai makna bahwa proses perubahan tingkah laku diakibatkan karena adanya interaksi antara individu dengan lingkungan dimana dirinya berada. Tingkah laku yang dimaksud terdiri dari aspek pengetahuan, keterampilan, dan sikap (Ardiyanto, 2014). Tingkah laku terbagi menjadi dua kelompok, yaitu yang dapat diamati dan yang tidak dapat diamati. Tingkah laku yang dapat diamati dikenal dengan behaviorial performance, sedangkan yang tidak dapat diamati dikenal dengan behaviorial tendency. (Hidayatulloh et al., 2018) Model pembelajaran untuk siswa ini dirancang dengan memperhatikan intesitas pembelajaraan pada setiap jenis permainan yang diberikan. Menurut (Lufthansa et al., 2019) pembelajaran merupakan kegiatan dimana adanya hubungan timbal balik dalam penyampaian informasi atau materi agar tujuan pembelajaran yang direncanakan dapat tercapai. Pendapat tersebut sependapat dengan (MS. Taufik, 2019) dapat di artikan bahwa mengajar adalah suatu aktivitas yang mengharuskan kita semua menjadi praktisi yang mudah menyesuaikan diri dan terus menerus mengajukan pertanyaan kritis tentang apa, mengapa, dimana, bagaimana dan kapan ketika sedang mengajar, serta melakukan penilaian.

Pembelajaraan lari jarak pendek (sprint) tidak dibentuk dalam permainan atletik dan memanfaatkan media dan 
Jurnal Kejaora: Jurnal Kesehatan Jasmani dan Olah Raga

ISSN: 2541-5042 (Online)

ISSN: 2503-2976 (Print)

Volume 6 Nomor 1, Edisi April 2021

pembelajaran yang ada, dalam artian semua siswa diminta untuk beraktivitas berlari, melompat maupun melempar dalam berbagai aktivitas bermain dan melihat dalam layar monitor tentang bagaimana rangkaian gerak atletik sehingga mempermudah informasi dan pemahaman siswa. Alat-alat serta tempat yang standar digunakan tidak harus selalu di lapangan namun yang paling penting informasi dapat di sampaikan melalui media yang tepat. Sasaran yang harus dicapai siswa sekolah menengah peratama (SMP) dalam memiliki dan menguasai berbagai kemampuan menurut (Widiastuti \& Hutomo, 2018) antara lain, gerak dasar lari, lempar dan lompat, atau dapat memiliki kemampuan motorik dasar seperti kekuatan, kecepatan, daya tahan, keseimbangan, dan kelentukan serta pembentukan nilai-nilai disiplin dan kerjasma. Hal tersebut merupakan hal yang paling diperlukan dibandingkan dengan dapat melakukan lompat jauh gaya jongkok sekian meter, tolak peluru sekian jauhnya, lompat tinggi sekian tingginya.

Berdasarkan hal tersebut penulis ingin mengubah atau mengembangkan pola pikir guru pendidikan jasmani dalam proses belajar mengajar Atletik: dari berorientasi prestasi kepada orientasi yang menginternalisasikan nilai-nilai pendidikan jasmani, olahraga dan kesehatan serta dari kebiasaan alat-alat standard yang digunakan, menjadi memodifikasi alat-alat berdasarkan pemanfaatannya. Dalam kegiatan atletik metode bermain sedikitnya komponen fisik siswa ikut turut tebina secara langsung. Menurut pendapat (Gantois et al., 2019) untuk memahami informasi yang relevan kemampuan otak manusia bekerja dalam pengambilan keputusan. Guru berperan dalam mengelola pembelajaran untuk mewujudkan nilai inti dari pendidikan jasamani tersebut. Menurut Pada umumnya suatu sekolah menempatkan lapangan beberapa cabang olahraga pada satu tempat dengan cara memberikan warna garis yang berbeda karena keterbatasan lahan yang dimiliki.

Tanpa bermaksud menyederanakan persoalan, yang memang tidak sederhana, penelitian ini menawarkan satu solusi fundamental, menurut (Febrianti,2013)

pembelajaran pendidikan jasmani olahraga dan kesehatan di sekolah dengan pengembangan model pembelajaran lari jarak pendek (sprint) dalam bentuk permainan dalam upaya pebentukan nilainilai disiplin dan kerjasama. Dengan penerapan metode bermain atletik pada pembelajaran lari jarak pendek (sprint) dalam upaya pembentukan nilai-nilai disiplin dan kerjasama diyakini sebagai solusi yang efektif. Menurut (Septiadi \& Widiastuti, 2019) Peranan atau wadah pendidikan dan latihan olahraga pelajar menjadi sangat dibutuhkan untuk mampu menjamin kelangsungan pendidikan olahragawan pelajar.

Konsep Pengembangan Model Menurut (Gall et al., 2003) Penelitian adalah usaha seseorang yang dilakukan secara sistematis mengikuti aturan-aturan metodologi seperti observasi sistematis terkontrol, mendasarkan pada teori yang ada dan diperkuat dengan fakta dan gejala yang ada Penelitian dapat pula diartikan sebagai cara pengamatan atau inkuiri dan mempunyai tujuan untuk mencari jawaban permasalahan atau proses penemuan, baik discovery, maupun invention. Dalam pelaksanaannya, setiap jenis penelitian memiliki cara-cara yang spesifik, (Hasibuan, 2019) sehingga seseorang perlu memahami terlebih dahulu jenis penelitian yang akan digunakan dalam penelitiannya sebelum memuali penelitian.

Jadi pada penelitian ini konsep yang akan dikembangakan adalah pengembangan model yangada untuk lari jangka oendek serta untuk anak smp kecamatan ciawi kabupaten bogor.

Berdasarkan temuan peneliti untuk menguatkan karakter konsep pengembangan serta latar belakang bahwa sebagai pembanding dengan penelitian sebelumnya yaitu menurut Pendapat (Asyhar \& Soedarto Harjono, 2012) pembelajaran lari jarak pendek di Sekolah menengah pertama adalah agar siswa mampu meningkatkan kebugaran jasmananinya melalui kegaiatan olahraga dan pengehalusan gerak dasar lari jarak pendek salah satunya lagi bahwa lari jarak pendek dalam Menurut (Perani et al., 2015) pembelajaran lari jarak pendek melalui permainan lari bola keranjang pada siswa sekolah dapat meningkatkan kemampuan 
Jurnal Kejaora: Jurnal Kesehatan Jasmani dan Olah Raga

ISSN: 2541-5042 (Online)

ISSN: 2503-2976 (Print)

Volume 6 Nomor 1, Edisi April 2021

belajar lari jarak pendek,Oleh karena itu peneliti agar lebih detail dan meluas terkait cakupan maka tujuan penelitian pengembangan adalah menghasilkan produk baru yang dipakai dalam ppembelajaran lari jarak pendek pada siswa Sekolah Menengah Pertama (SMP).

Bedasarkan latar belakang masalah di atas, penulis mengambil kesimpulan bahwa perlu adanya rancangan model pembelajaraan yang dirumuskan menurut (Haqiyah et al., 2017) model pembelajaran yang baik, kreatif dan inovatif disesuaikan dengan fase-fase perkembangan gerak siswa, oleh karena itu peneliti ingin berkontribusi membuat suatu model pembelajaran yang kreatif dan inovatif sehingga tujuan pembelajaran secara optimal dapat dicapai. Menurut (Abrasyi et al., 2018) gerak yang benar dan adanya latihan yang rutin secara sistematis model yang dibuat dapat memberikan contoh pelaksanaan kepada guru dalam menyampaikan materi dalam pembelajaran pendidikan jasmani.

\section{METODE}

Penelitian ini menggunakan pendekatan kualitatif dan kuantitatif. Tujuan penelitian ini adalah mencari rancangan model pembelajaran lari jarak pendek. Penelitian pengembangan hasil akhirnya adalah model pembelajaran pendidikan jasmani pada materi keseimbangan dimana akan menghasilkan produk berupa pembelajaran yang lengkap dengan spesifikasi produknya sekaligus menguji efektivitas dari model pembelajaran yang telah dibuat, sehingga dapat meningkatkan keterampilan lari jarak pendek peserta didik dan dapat juga digunakan sebagai pegangan dalam kegiatan belajar mengajar pendidikan jasmani. Dalam penelitian dan pengembangan pembelajaran menggunakan pendekatan kualitatif dan kuantitatif serta menggunakan model

Pengembangan Research \& Development (R \&D) dari (Gall et al., 2003)yang terdiri dari sepuluh langkah.

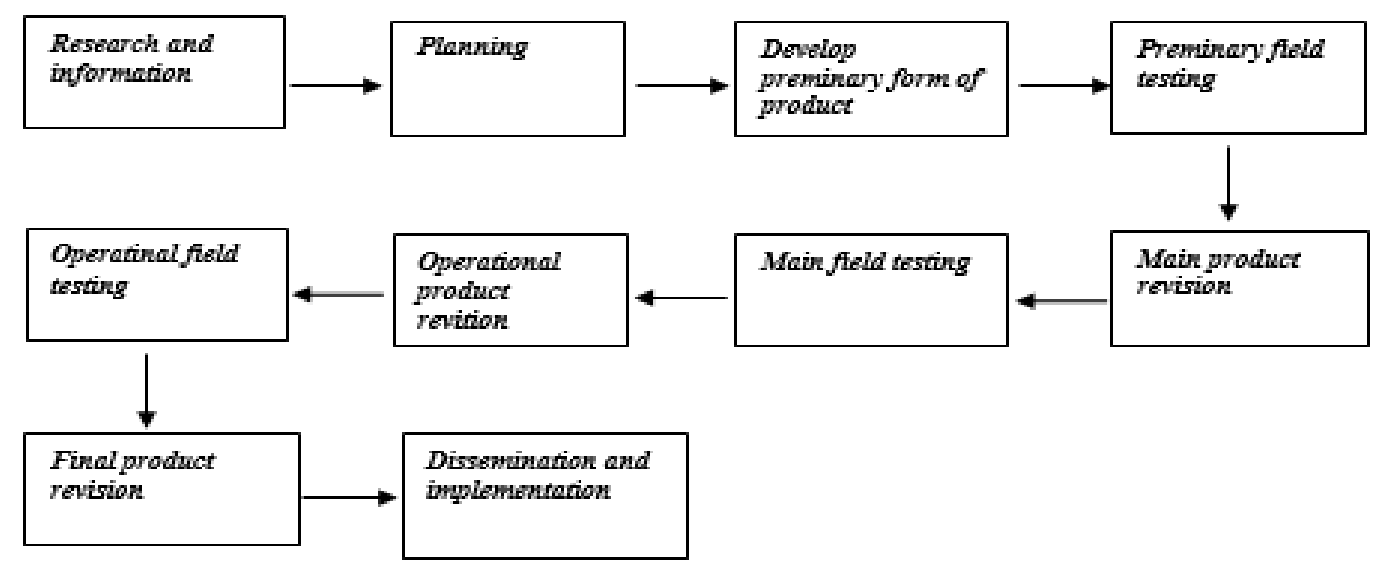

Gambar 1. Instructional Design R \& DSumber: Walter R. Borg and Meredith D. Gall, (Gall et al., 2003)

Teknis analisis data dalam penelitian diawali dengan pendekatan kuantitatif yang bertujuan untuk mencari efektifitas dengan rancangan penelitian true-experiment dimana desainnya dipih dua kelompok secara random, kemudian diberikan pretest untuk mengetahui keadaan awal sehingga diketahui perbedaan antara kelompok eksperimen dan kontrol. Pada saat uji coba penelitian langkah yang dilakukan antara lain; (1) subjek membentuk kelompok penelitian; (2) melakukan pretest (01); (3) mencobakan model yang telah dikembangkan; (4) melakukan post-test (02); (5) menghasilkan skor pre-test rata-rata dan post-test serta dibandingkan antar keduanya; (6) membandingkan selisih hasil dari kedua ratarata melalui metode statistik (uji-t) untuh mengetahui pengaruh yang signifikan dari penggunaan model. 
Jurnal Kejaora: Jurnal Kesehatan Jasmani dan Olah Raga

ISSN: 2541-5042 (Online)

ISSN: 2503-2976 (Print)

Volume 6 Nomor 1, Edisi April 2021

\section{HASIL DAN PEMBAHASAN}

Berdasarkan uji ahli yang dilakukan dapat ditarik kesimpulan bahwa ada 4 model pembelajaran yang tidak valid dari 16 model. Dengan demikian ada 12 variasi model pembelajaran lari jarak pendek dengan sirkuit layak dan dapat digunakan dalam model pembelajaran lari jarak pendek untuk siswa SMP. Terdapat beberapa saran yang membangun dari hasil uji ahli yang dilakukan oleh tiga ahli, dimana saran tersebut merupakan saran yang membangun untuk menyempurnakan model pembelajaran lari jarak pendek diantaranya: 1) model pembelajaran yaitu harus sesuai dengan usia anak Sekolah Menengah Pertama (SMP); 2) Tingkat keamanan perlu diperhatikan; 3) Petunjuk pelaksanaan model pembelajaran lari jarak pendek harus dibuat secara jelas agar mudah dipahami; 4) Agar tidak membuang waktu dalam pelaksanaan model ini, ukuran lapangan permainan ini harus diperjelas agar mudah dipahami; 5) Jarak antar siswa yang mengikuti dalam permainan ini harus diperhatikan; 6) Permainan ini senantiasa dijelaskan karena siswa yang melakukan belum tentu memahaminya.7) Perbaikan pembelajaran 8) Revisi dan efektifias 9) Impelentasi produk 10) Pemasaran produk dan penjelaskan produk pembelajaran lari jarak pendidik.

\section{Efektivitas Model}

Hasil dari uji coba yang telah dilakukan dijadikan dasar bagi peneliti untuk menentukan bahwa pembelajaran yang dikembangkan efektif digunakan dalam proses pembelajaran lari pendek yang dlakukan oleh siswa Sekolah Menenga Pertama (SMP). Berikut merupakan pemaparan masing-masing data hasi uji coba. Hasil evaluasi uji coba kelompok besar terhadap produk pengembangan model pembelajaran lari pendek pada mata pelajaran pendidikan Jasmani, Olahraga dan Kesehatan menggunakan 120 orang peserta didik dari 3 Sekolah Menengah Pertama (SMP).

Kegiatan uji coba kelompok besar dilaksanakan pada bulan Maret 2019.Penelitian dilakukan di tiga sekolah menengah pertama di Kabupaten bogor, Sekolah Menengah Pertama Negeri 2 ciawi Bogor, Sekolah Menengah Pertama Negeri 1 ciawi Bogor dan Sekolah Menengah Pertama Negeri 3 ciawi Bogor. Data diambil dengan cara memberikan instrumen pembelajaran lari jarak pendek.Berdasarkan analisis data diperoleh dengan mengunakan SPSS 16 nilai rata-rata sebelum tes 57.85 dan rata-rata sesudah tes 63.85, pada pengujian perbedaan menggunakan SPSS.

Tabel 1. Paired Samples Correlations

\begin{tabular}{llll}
\hline & N & t & Sig. \\
\hline Pre_Test Post_Test & 120 & -23.542 & .000 \\
\hline
\end{tabular}

Nilai t -23.542 taraf signifikasni 0,05 . Kesimpulan menunjukan $\mathrm{HO}$ ditolak, terdapat perbedaan antara hasil pembelajaran lari jarak pendek peserta didik setelah diberikan model pembelajaran lari jarak pendek pada tes awal dan tes akhir. Berdasarkan hal tersebut bahwa model lari jarak pendek pada pembelajaran yang dikembangakan efektif meningkatkan hasil lari jarak pendek. Berikut perbandingan rata-rata dari tingkat pembelajaran lari jarak pendek sebelum pemberian treatmen dan sesudah pemberian perlakuan dengan model pembelajaran lari jarak pendek dengan diagram batang: 
Jurnal Kejaora: Jurnal Kesehatan Jasmani dan Olah Raga

ISSN: 2541-5042 (Online)

ISSN: 2503-2976 (Print)

Volume 6 Nomor 1, Edisi April 2021

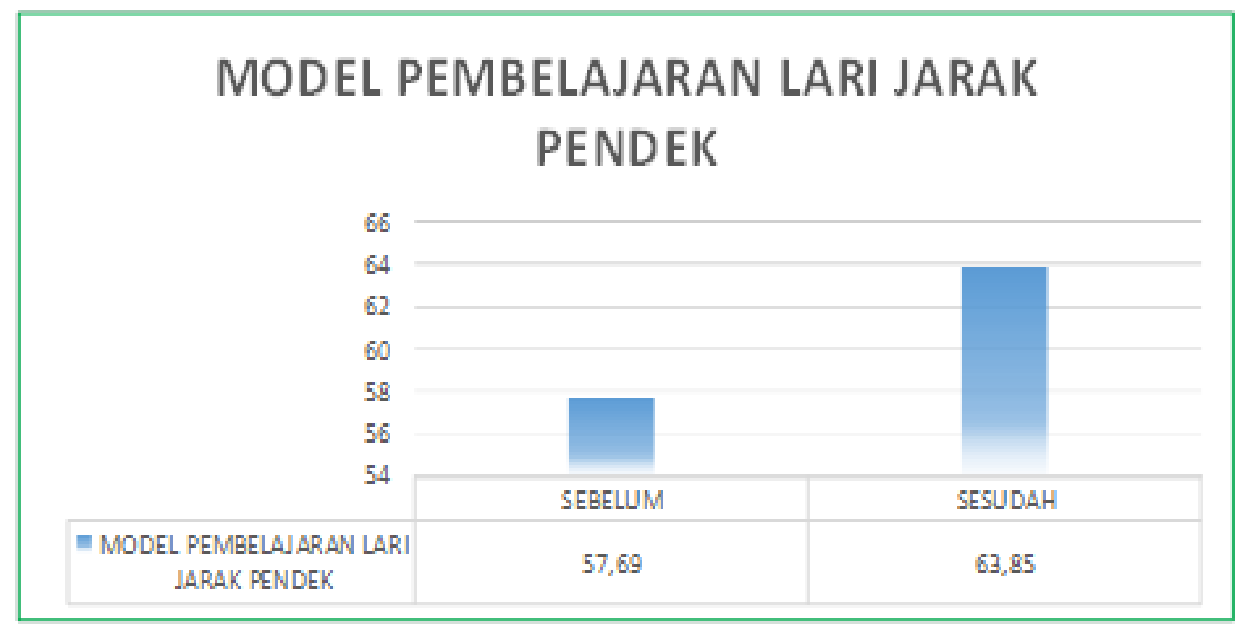

Gambar 2. Diagram Batang Sebelum dan sesudah diberikan perlakuan

Dari diagram batang di atas menunjukan bahwa ada peningkatan yang signifikan sebelum dan seduah diberikan model pembelajaran yang telah dikembangkan.Dapat disimpulkan bahwa model pembelajaran lari jarak pendek dapat digunakan model lari jarak pendek pada pembelajaran olahraga di sekolah menengah Pertama.

\section{PEMBAHASAN}

Tujuan dari penelitian ini menggunakan pengembangan metode penelitian Research \& Development (R \& D) dari Borg and Gall kemudian dengan pendapat Menurut (Kramers et al., 2020) efektifitas pembinaan sebagai "penerapan konsisten pengetahuan profesional, interpersonal, dan intrapersonal yang konsisten untuk meningkatkan kompetensi, kepercayaan diri, koneksi, dan karakter atlet dalam konteks pelatihan khusus. Berdasarkan hasil perhitungan diperoleh kesimpulan bahwa model pengembangan pembelajaran lari jarak pendek yang dibuat efektif dalam pembelajaran pendidikan jasmani terutama pada materi model pembelajaran lari jarak pendek pada siswa SMP. Dapat di lihat pada nilai rata-rata sebelum tes 57.85 dan rata-rata sesudah tes 63.85. Menurut (Teatro et al., 2017) keefektifan seorang pelatih adalah penting untuk dapat lebih memahami jiwa atlet dan dapat menyebabkan peningkatan kinerja olahraga secara signifikan. Menurut (Kao et al., 2017) "Kompetensi pembinaan telah berkembang menjadi topik penelitian dan telah semakin meningkat minatnya dalam bidang pembinaan olahraga selama dekade terakhir. Hasil ujicoba kelompok besar penggunaan model pembelajaran lari jarak pendek ini ternyata menghasilkan $84 \%$ dari target yang diharapkan, artinya model ini sudah efektif untuk memenuhi kebutuhan pembelajaran lari jarak pendek untuk siswa sekolah menengah pertama. menurut (Bolter et al., 2018) Pelatih memainkan peran penting dalam menentukan kualitas pengalaman ini, dan program pelatihpendidikan dan sertifikasi pelatih telah dirancang untuk mempersiapkan pelatih untuk peran penting mereka dalam pengaturan olahraga'.

\section{KESIMPULAN}

Berdasarkan hasil data yang di peroleh pada hasil kelompok uji coba kecil dan besar diperoleh kesimpulan: 1) Model pembelajran lari jarak pendek dapat diterapkan pada siswa sekolah menengah pertama yaitu pada tiga sekolah di Bogor. Sekolah Menengah Pertama Negeri 2 Ciawi Bogor, Sekolah Menengah Pertama Negeri 1 Ciawi Bogor dan Sekolah Menengah Pertama Negeri 3 Ciawi Bogor. 3) Berdasarkan hasil uji efektifitas model, terbukti bahwa hasil produk berupa pengembangan model pembelajaran lari jarak pendek bagi siswa sekolah menengah pertama (SMP), yang 
Jurnal Kejaora: Jurnal Kesehatan Jasmani dan Olah Raga

ISSN: 2541-5042 (Online)

ISSN: 2503-2976 (Print)

Volume 6 Nomor 1, Edisi April 2021

diaplikasikan dengan permainan, memiliki efektifitas yang sangat baik.

\section{DAFTAR PUSTAKA}

Abrasyi et al. (2018). Model Latihan Passing Bawah Bola Voli Pada Siswa Sekolah Menengah Pertama. Journal Sport Area, 3(2), 168-178.

Asep Ardiyanto, Pamuji Sukoco S. (2014). Pengembangan Model Pembelajaran Berbasis Permainan Tradisional 119. Jurnal Keolahragaan, 2(1), 119-129.

Asyhar, R., \& Soedarto Harjono, H. (2012). Pengembangan Media Audio-Visual Pembelajaran Lari Jarak Pendek Untuk Siswa Smp. Tekno-Pedagogi, 2(1), 1-21.

Bolter, N. D., Petranek, L. J., \& Dorsch, T. E. (2018). Coach, parent, and administrator perspectives on required coaching education in organized youth sport. International Journal of Sports Science and Coaching, 13(3), 362372.

https://doi.org/10.1177/17479541177 35718

Bompa, T., \& Carrera, M. (2015). Conditioning Young Athletes.

Febrianti, R. (2013). Pengembangan materi atletik melalui permainan atletik. Semarang, Universitas Negeri Semarang, 2(1).

Gall, M. D., Gall, J. P., \& Borg, W. R. (2003). Epdf.Pub_Educational-Research-anIntroduction-7Th-Edition.Pdf.

Gantois, P., Elisa, M., Ferreira, C., Limajunior, D. De, Nakamura, Y., Batista, G. R., Fonseca, F. S., \& De, L. (2019). Effects of mental fatigue on passing decision- making performance in professional soccer athletes. European Journal of Sport Science, $0(0), \quad 1-21$. https://doi.org/10.1080/17461391.201 9.1656781

Haqiyah, A., Mulyana, M., Widiastuti, W., \& Riyadi, D. N. (2017). The Effect of Intelligence, Leg Muscle Strength, and Balance Towards The Learning Outcomes of Pencak Silat with EmptyHanded Single Artistic. JETL (Journal Of Education, Teaching and

Learning), https://doi.org/10.26737/jetl.v2i2.288

Hasibuan, M. H. (2019). Pengembangan Model Latihan Passing Dan Receiving The. Gladi Jurnal, 5(1), 217-240.

Hidayatulloh, D. T., Asmawi, M., Sujiono, B., \& Jakarta, U. N. (2018). Model Latihan Berbasis Permainan Meningkatkan Daya Tahan Cardiorespiratory Atlet Pencaksilat Usia SMP. Journal Sport Area, 3(2), 131-139. 2018.vol3(2).

https://doi.org/https://doi.org/10.25299/sporta rea.

Kao, S. F., Hsieh, M. H., \& Lee, P. L. (2017). Coaching competency and trust in coach in sport teams. International Journal of Sports Science and Coaching, 12(3), 319-327. https://doi.org/10.1177/17479541177 10508

Kramers, S., Turgeon, S., Bean, C., Sabourin, C., \& Camiré, M. (2020). Examining the roles of coaching experience and coach training on coaches' perceived life skills teaching. International Journal of Sports Science and Coaching.https://doi.org/10.1177/174 7954120922367

Lufthansa, L., Susilo, S., Zaini, M., Kusmawati, W., Rah, P., Pawitra, A., Anugraini, A. P., Budi, I., \& Malang, U. (2019). Pengembangan Buku Ajar IImu Gizi Olahraga: Studi Motivasi Dan Hasil Belajar Development Of Sports Nutrition Textbook: Study Of Motivation And Learning Results. Journal Sport Area, 4(2), 327-338. https://doi.org/https://doi.org/10.25299 /sportarea.2019.vol4(1).3863 How

Mitchell, L. J. G., Rattray, B., Fowlie, J., Saunders, P. U., \& David, B. (2020). The impact of different training load quantification and modelling methodologies on performance predictions in elite swimmers. European Journal of Sport Science, $0(0), \quad 1-29$. https://doi.org/10.1080/17461391.202 0.1719211

MS. Taufik. (2019). Hubungan Tingkat Konsentrasi Dengan Keterampilan Bermain Futsal Unit Kegiatan 
Jurnal Kejaora: Jurnal Kesehatan Jasmani dan Olah Raga

ISSN: 2541-5042 (Online)

ISSN: 2503-2976 (Print)

Volume 6 Nomor 1, Edisi April 2021

Mahasiswa Futsal Universitas Suryakancana Dalam Olahraga. Gladi Jurnal UNJ, 10(02), 68-78. https://doi.org/DOI :

https://doi.org/10.21009/GJIK.102.01

Perani, I., Hidasari, F. P., \& Triansyah, A. (2015). Pembelajaran Lari Jarak Pendek Menggunakan Pendekatan Permainan Lari Bola Keranjang Pada Siswa Sd. Jurnal Untan, 2(2), 1-9.

Prasetya et al., T. D. (2018). JUARA : Jurnal Olahraga. JUARA: Jurnal Olahraga, 3(2).

http://jurnal.upmk.ac.id/index.php/juar a

Putro, B. N., Kurniawan, A., \& Fudin, M. S. (2018). Pengembangan Buku Pedomanman To Man Defense Bola Basket Untuk Pelatih. Journal Sport Area, 3(2), 111. 2018.vol3(2).2326 https://doi.org/10.25299/sportarea.

Septiadi \& Widiastuti, H. (2019). MODEL LATIHAN SPEED Endurance Berbasis Senam Pencak Silat Untuk Usia Remaja. Journal Sport Area, 4(2), 285-293. 2019.vol4(2).1803 https://doi.org/https://doi.org/10.25299 /sportarea.

Tawing Trenggalek. (2018). Peningkatan Hasil Belajar Lari Cepat 100M Melalui Metode Latihan Akselerasi. Vol., 2(1), 24-29.

Http://Journal.Unublitar.Ac.Id/Pendidi kan/Index.Php/Riset_Konseptual

Teatro, C., Thompson, M., Kulinna, P. H., Van Der Mars, H., \& Kwan, J. Y. (2017). Coaching behaviors and stakeholders' views of coaches' efficacy. International Journal of Sports Science and Coaching, 12(4), 452460.https://doi.org/10.1177/17479541 17718094

Widiastuti, \& Pramudito Hutomo. (2018). Meningkatan Keterampilan Lompat Jauh Gaya. 09(01) JUARA: Jurnal Olahraga. JUARA: Jurnal Olahraga, $56-67$ 